\title{
The Sustainable Protection of Intangible Cultural Heritage Information in Digital Era
}

\author{
Cheng Yang, Long-wei Wu \\ City College, Zhejiang University, Hangzhou, P.R. China
}

\begin{abstract}
The traditional approach has been insufficient to support the huge burden of the cultural heritage preservation and maintenance. Lots of intangible cultural heritage would disappear. In web time, Modern digital technology and network technology enhanced the protection efforts and efficiency of cultural heritage. With the popularity of digital protection methods, there were increasingly difficulties, such as the lack of funding and concept for post-maintenance; the dynamic changes in the environment, the complex format of digital file, the lack of public support and the problem of information management brought by intellectual property rights. With the current technological level and financial support, if wanted to achieve the sustainable development of digital preservation of cultural heritage, we should establish evaluation criteria on information as soon as possible and emphasize on the collaborative conservation and hybrid protection for the pursuit of cost-effective optimization, try to maintain a relatively stable environment of protection at the same time, vigorously promote the significance of digital protection, avoid or reduce the information loss and waste of resources in the process of refreshing information and avoid dilemma of using information.
\end{abstract}

Index Terms - Intangible cultural heritage; Network society; Informational ecosystem; Sustainable protection.

\section{Introduction}

During the transition from the agricultural civilization to the modern civilization, a plenty of cultural heritage are facing a disappearance, especially the intangible cultural heritage. Cultural inheritance and promotion encounters certain challenges and crises. Intangible cultural heritage protection in the traditional sense is based on the paper text, graphics and objects, which communicate to the public through the display of a fixed venue. Traditional protection requires large amount of manpower and spaces, and it is inconvenience to maintain and arrange. In addition, it is not efficient to use and transmit cultural heritage

With the arrival of the digital era, the development of information technology and virtual reality technology have changed our perception of time, space and living condition. And they provide a new way and possibility to solve the problem of the intangible cultural heritage protection. Network society is a new kind of social structure, which is from the interaction of the social organizations, the social changes and the technology model are composed of digital information technology. Intangible cultural heritage protection constructs a multi-dimensional cultural content dissemination and diversified forms of the intangible cultural heritage through the Internet and information technology. It speeds up the strength and efficiency of protection, and also promotes the intangible heritage in network society. The government functional departments, experts and scholars have made a lot of work in the field of information protection of intangible cultural heritage, and accumulated a large amount of information. But only the intangible information technology acquisition and storage are unable to ensure the effective inheritance. How to organize and manage the information resources is the key to long-term protection. As for a great amount of saved information and the information which is will be saved ,It is a heritage to survive in the modern information world to make the digital and networked environment better and save for a long time.

\section{The Information Attribute of Intangible Cultural Heritage}

A. Viewed the Information Attribute of Intangible Cultural Heritage from Its Definition

According to the definition in the Convention for the Safeguarding of the Intangible Cultural Heritage which was passed by the UNESCO, "intangible cultural heritage" refers to those groups, organizations, and sometimes all kinds of practices, performances, forms, knowledge and skills and its relevant tools, material objects, handicrafts and cultural sites that was considered as cultural heritage by individuals. Groups and organizations promote innovation of the intangible cultural heritage inherited from one generation to another with the constantly changes of its environment, the relationship of the nature and historical conditions, and make themselves have a sense of identity and history. Thus ,this will promote the cultural diversity and stimulate the creativity of human beings.

According to the definition of the intangible heritage, the subject is the intangible culture such as skills and knowledge, which has strong information attribute. From the perspective of information, intangible cultural heritage is the information organized in a particular form. And it is a form of information produced in the agriculture age environment when the inefficient information is disseminated.

\section{B. Viewed the Global Cultural Convergence from the Information}

In modern society, Information flows rapidly. Emerging media model and information technology offered a chance for wide culture spread, which led to the modern process of cultural globalization. Many citizens fear that their traditional values, languages and habits will influenced by the foreign culture, especially the impact of western culture. Economist Tyler referred that the development of globalization promoted the technology and productivity in a lot of areas that was originally underdeveloped in a very short period of time in the 
creative destruction. But he also added that we should see the expansion of the European and American culture in overseas makes the world more and more similar, which is actually harmful to the innovation and cultural diversity.

In fact, the global cultural information sharing and communion do not lead to a long-term convergence of culture. In the process of cultural sharing and exchange, every community, ethnic group and national will better construct and nourish its host culture. [4] Sharing process is actually a process of selection and learning. In a short period of time, some areas whose economy, science and technology are disadvantaged, will appreciate strong regional development achievements and absorb the excellent science and technology culture widely. This eventually results in a similar phenomenon of part of culture. In fact, for a country with a long history, its connotation characteristics of cultural subject is still exists. But just for a period, the connotation characteristics will be masked under the extensive imitating appearance. In the case of the strength gap of both sides is narrowing, the original disadvantaged areas necessarily show new cultural differences due to its own history, geographic conditions and social environment is different. This difference comes from the bloodline of the original culture and the spontaneous demanded for cultural diversity and human heart.

\section{Efficient Information Dissemination Assists the Intangible Cultural Heritage in Protection}

The rapid development of information technology led to the rapid blend of cultures of most areas and the transient cultural convergence. At the same time, it also provides a strong support for the heritage protection. In modern society, a major factor that makes the public to concern about the nonmaterial cultural heritage protection is the emergence of the information society. The development of digital and network technology makes it possible for the non-material cultural heritage which is disappearing from public fields to return to people's sight. [5]Protecting the heritage with the digital technology can strengthen the protection strength and efficiency, but also promote the spread of intangible heritage in the information age. And it makes the innumerable arts and crafts which possess the historical value break through the original technical conditions, space constraints, time limit for communication, thus let the public can enjoy the ancient art and the beauty of creation. Additionally, the endangered cultural activities can be dynamic reappeared and presented, people are able to see the history, and get profound understandings of cultural development and evolution. Yet in the transformation of network social, intangible cultural heritage environment has changed a lot. Currently, intangible cultural heritage information is facing a problem that its survival way have taken place in a new environment.

\section{The Bottleneck Problem of the Sustainable Protection of Intangible Cultural Heritage under the Perspective of Information}

We use information technology to protect the heritage, but who protect the digital information itself? Units cost Millions or even ten million of money at the digitization of the existing intangible cultural heritage. But who is responsible for the maintenance of these information resources for a long time? How to save and maintain these special information for a long time? In theory, the digital information preservation is not complicated. As long as good hardware, software, environment and professional technical maintenance personnel these three elements are possessed, the information can be preserved for a long time. The problem is the limitation of time and money, which causes it hard to continue to satisfy the three elements at the same time.

\section{A. The Instability of Protection Environment}

The first problem of the protection work is that of the software and hardware environment of the intangible cultural heritage information protection is not stable. The main challenge of the intangible cultural heritage protection is not a technical question, but a social problem. In the capital era when the competition is fierce, the appropriate obsolete hardware and software products is the key of enterprise survival and development.[6] The rapid development of technology and product updates, is the assurance of continuous enterprise profits. But rapid change of the technology led to frequent update of the hardware and software environment where digital information is saved. It is needed to continually organize manpower and material resources to migrate the original enormous intangible cultural heritage information to new hardware and software environment.

\section{B. Abundant and Miscellaneous Information}

Along with the progress of science and technology, humanities and natural science are booming. And a large number of new knowledge of science and technology literature and art are produced every day. These scientific knowledge, professional literature, literary works and intangible information came to the library, stored in various kinds of large capacity storage device or the entire computer system. Increasing numbers of various stored Information complicate the management and maintenance work in libraries. Huge amounts of information swarm into this unstable digital preservation environment, bringing great challenges of the protection work. A large amount of digital information has been lost forever, and some familiar coded information will disappear at any moment. The saved digital information is likely to miss or become inaccessible due to the mismanagement, outdated word processors, the old database format, hardware damage or improper filing. Many large database in governments and universities become obsolete due to technological changes, thus some information is discarded or is expensive to rescue. Because of natural disasters, virus and human factors, storage hardware may also be damaged, leading to the information loss. [7]It is responsible for the digital archive information department to develop a set of effective fail-safe mechanism, which can rescue possible loss of information.

\section{Various and Incompatible Document Formats}

Types of the digital file format is too various and incompatible, increasing the difficulty of the protection. It is 
easy to copy the original file from one storage device to another. However, merely copying digital information for the intangible cultural heritage protection is not enough. Complex and incompatible file formats often let the old information cannot be browsed and used. Modern enterprises are required to chase a new growth point, which will speed up the outdated technology. At the same time as the pursuit of new product performance, they often do not consider to be compatible with existing technology, resulting in a large number of new formats. This kind of circumstance is in negative resistance to establish a standardized stable protection system including hardware, software, and management. [8]

Libraries, cultural centers and museum collection agencies often have to use a wide variety of digital formats. This is because many collections of digital information are not only to preserve and digitize originally, but due to some specific functions. These digital resources that are from the originator or content providers are different from each other in the aspects of the storage medium, data format, and even retrieval way. When the libraries manage these resources, they will find that it is very complex to maintain the integrity of the link files, handle with the background of the script file, save the embedded object and dynamic multimedia files with programming content. This is almost an impossible task.

\section{The Commercialization of Knowledge}

The commercialization of knowledge complicates the intangible cultural heritage work, so many precious intangible cultural heritages are considered as private assets. The privatization and the intrinsic properties of intangible cultural heritage are contradicts. The shift from non-material culture to the intangible cultural heritage is one kind of mechanism of public culture. Intangible is different from general knowledge. For example, the author of the novel possess the copyright, and others can't claim the same rights. But it can produce different non-material cultural project claims, and one of the most prominent is the ownership and usufruct of compatibility. Heritage and heritage areas may claim that they possess an the intangible cultural heritage, but more a wide range of subjects can claim it and use it which also brings profits. [9] The intervention of a larger scope of subjects makes the the intangible cultural heritage more valuable.

But more and more strict protection of intellectual property rights system prevents many key intangible information from being collected and preserved in libraries. Many intangible cultural heritages are considered as private assets, therefore inheritors won't store them in the public libraries with no substantial economic benefits. Many folk art heritages can easily gain huge commercial interests and social recognition by virtue of their family's knowledge and skill. In the porcelain firing techniques, for example, glaze formula is the core of the whole production process, and it only spreads in the family way, which is strictly confidential between porcelain making master. No master artisans will save their own unique formulas to in public libraries, so, the related resources in the library was only a part of some basic information. The European digital library program hosted by the national library in Hague in Netherlands, will file the digitization 20 centuries ago. A major limiting factor is that many modern works is still protected by copyright, which means they should be digitized and released only authorized by the copyright owner. [10]

From the positive point of view, the protection of intellectual property rights makes the intangible cultural heritage protection institutions don't have to save key information resources, which can be preserved by their holders themselves. But whether the private owners is public-spirited and provide these precious resources for future generations? When some important heritage information becomes business owners' personal assets, the enterprises will become the places where most valuable information is retained. But companies did not promise to save the existing information effectively for a long time. This means that when the information loss, there would be no official agencies know what happened, and it is more impossible to stop the loss of information. Afterwards, no one need to be responsible for the loss of related cultural heritage.

\section{E. The Lack of Late Maintenance Concept}

The lack of maintenance concept is the root of the difficulty of the lasting effective heritage protection work. In recent years, our country strongly support the protection of the intangible cultural heritage, and government entities at all levels are actively invest a lot of manpower and financial resources to the high-tech protection [11].Many museums, libraries across the country spend millions or even tens of millions of money to digitize the existing paper and physical data, including the building of a legacy database, digital image and video, the reconstruction of $3 \mathrm{D}$ digital model, and even 3D intangible cultural heritage video for visitors. However, who is responsible for long-term maintenance of the digital information after spending a huge sum of money to get these digital information resources? How much maintenance budget should be in every year? Who will check the storage hardware problems? If the information is lost, the collection entity will be responsible for what kind of duty? All these problems have not been defined and effectively incorporated into public policy. The existing protection units are numerous, and their fiscal expenditures have increased year by year. Relative to the personnel expenditure, infrastructure construction, hardware and software purchase cost, the money spent on information resources to maintain effective financial resources is less or even no every year. In a short term, there is no signs of improvement.

\section{F. The Lack of a Wide Range of Popular Support}

The change of the times is the root of the decline of the intangible cultural heritage, which causes most intangible cultural heritage individuals become difficult to satisfy the modern aesthetics and people's living demand, thus it was short of public support and durability. The intangible cultural heritage protection problem hasn't really came to the attention of the public and is short of social enthusiasm. Part of the heritage protection project is just to get more financial support from the state and governments at all levels, or to win more local publicity, promoting the local tourist economy. For 
ordinary people, the heritage protection is still a profound and distant issue, and only the government and a few experts are concerned about it. Even though protection agencies spend a huge sum of money to get a large number of intangible cultural heritage information, they only intend to get the data stored in all kinds of storage hardware. For long-term preservation, protection units haven't do a detailed plan. In a few years or even decades later, whether these digital information can be read and displayed is not the point of the concern currently.

\section{The Survival Factors of the Intangible Cultural Heritage Information}

If the survival system of intangible cultural heritage is regarded as an ecosystem, the three decisive basic elements of intangible cultural heritage information are people, intangible individual and the environment. As with the natural ecosystem, intangible information ecosystem is an entirety consists of different parts that may relate and depend on each other. The core of the whole system is people, includes users, consumers and transmitters. Sometimes, the status can be overlapped, for example, someone is both an intangible heritage's transmitter and user. The various elements work together in the legacy information system, and form a sound ecosystem. Among them, the people's demand, abundant intangible information and good intangible information environment is the power which can promote the system.

\section{A. People's Demand}

The need of people or the public recognition of intangible degree is the most important factor. It generates, develops and evolves in the history. The evolution is based on the changes of the times which is the guidance and follows the rules in people's material and spiritual needs. The communication and the sharing of intangible cultural heritage in general public is the basis of long-term existence of Intangible information. If individuals want to survive in the ecosystem, not only good institutional environment, but also the enough supply of the ecological resources are needed. The ecological resources include enough users, transmitters and consumers. Otherwise, no one want to use the saved intangible information which can only be a numeric code on the computer.

\section{B. The Informational Living Environment}

Wholesome protection system, effective management and advanced information technology are the necessary securities which can optimize the living environment. The needed resources in the heritage protection are huge. Too extensive management and broad protection scope lead to huge fiscal spending and low efficiency, which is not conducive to the sustainable development of protection. Some local governments attach importance to the declaration instead of the protection. They declare the culture that is related to the intangible cultural heritage, but citizens hold the mentality of watching on the sidelines. At this stage, it is necessary to define the scope of the heritage protection, clarifying some intangible types or their important parts that need the protection. All kinds of cultural heritages have no ranking points in the survival identity, but they are different in their social value, artistic value, economic value and the difficulty of protection. Therefore, in addition to the definition of protection scope, the levels of protection and assistance also should be clear. In the different stages of protection work, the corresponding protective effect evaluation is needed. It is used to monitor the protection work which should continues to advance, otherwise, ending this phenomenon will become difficult.

Advanced information technology provides support conditions for survival of the intangible cultural heritage. There are many types of the achievements forms of intangible information protection, such as electronic documents, digital video, interactive display system based on the Internet, virtual museum, electronic books, cultural symbol library and so on. There is a large difference among the digital demonstration forms, traditional papery and physical demonstration forms, and the former are more convenient, intuitive and efficient. The convenience of the search, the freedom of the data manipulation, the achievements and audiences' interaction, and the enjoyment of the demonstration forms [13] all have promoted the spread of culture and learning. Currently, digital protection has been widely used and gradually becomes a mainstream way of cultural heritage protection. With the popular of Internet, the digital information service must be provided if the modern library collection units would like to make progress. But the abilities of the museums and libraries are limited in cope with huge digital resources. Besides, publishers dump various spam to the library collection units, storing abundant less-valued information there. To solve these problems, besides the legal system, a wider range of support and social understanding is also needed.

\section{Accumulation of Intangible Cultural Heritage}

The long-term accumulation of the intangible cultural heritage information is the foundation of the existence of intangible information ecosystem. At the same time, the authenticity and effectiveness of information are also important. In many cases, the overload, monopoly and pollution of the information have led to the deterioration of heritage protection work. Flood of information often makes people confused. Information overload has become not only the crushing burden of organizations and individuals that would like to access the information, but will result in serious waste and cover real and effective information. [12] The development of the network results in a lot of redundant information, false information, dislocation and outdated information, which not only hinder the human to absorb and use valuable information, but cause serious consequences in the realm of spirit in the whole society.

\section{The Sustainable Protection of Intangible Cultural Heritage Information}

Information technology dramatically changes the social environment around the world. That just like the industrial revolution which changed the world in the 19th century, and the enormous social and technological change has changed the living environment of traditional culture. New economic 
growth mainly depends on the information and knowledge, rather than the production of the item. The development of digital and network technologies offers endless possibilities for intangible cultural heritage information preservation and dissemination, but the technology alone is not enough to achieve lasting protection.

\section{A. Systematic Information Evaluation Index System and Informational Effective Filtering}

The protection of intangible cultural heritage requires quantitative or qualitative index system, that can help us evaluate protection scope, the level of protection, protection standards and the enforcement. The heritage protection work is significant, but it does not guarantee the permanent survival of all protected intangible cultural heritage. It not only because some intangible cultural heritages themselves are unable to survive, there are deep social reasons. Intangible cultural heritage has a wide range, and it requires corresponding ecological resources to support its survival and development. Besides, its ecological resources is similar to the biological resources, which is rich but still limited. Each person can carry limited cultural skills, habits and customs, and this determines the living space of intangible cultural heritage community is limited. Too generic protection will only weaken the protection, losing the direction and the focus.

Intangible cultural heritage information is so huge, it brings great ongoing pressure to protect the unit. As long as protected information is valuable, this pressure will always exist. Maintenance and management of the workload will continue to expand with the amount of information increases every year storage. In the case that the protection financial and staffing can not be significantly improved, the protection unit must do some "downsizing" campaign to reduce the burden of protection. In fact, the digital collection agencies already know that not all information can and should be saved. The key lies in determining what digital resources worthy of preservation, which is not worth it. Cultural protection departments must formulate guidelines of the digital collections' development and evaluation, and helping determine what can be saved and what is not worth saving, and how to save. We need to inspect and clean the existing collection of information one by one, eliminating useless and duplicate information. Establish a standardized digital information evaluation, selection, and maintenance is the key tasks to protect digital information of intangible cultural heritage in the future.

\section{B. Stable Intangible Cultural Heritage Information Environment}

Intangible cultural heritage protection work has complex nature. The purpose of intangible cultural heritage protection is more than just saving, we also need to disseminate culture. We need to promote these "essence" to the local where it is needed, impacting the public, promoting the development of society. So, it is inevitable that we spread digital information through network technology. According to the current development pace of digital technology, we will not know which software can read the files that are saved now in a few years later. The types of digital formats is a social problem, we can not approach forced by "one size fits all", ordering all companies and individuals to use a unified format. Mixed media and multiple document formats will remain in the field protection of digital information. In the future for a long period of time. Current Situation that there are too many information stored formats exist, require us to maintain several multiple software or hardware platform at the same time, thus making simply copy work of intangible cultural heritage information complicated.

In the foreseeable future, it is impossible that the intangible cultural heritage information can be stored in a common required format. A lot of people are counting on the development of format conversion software, but now the results are not satisfactory. Since within a fairly long period of time, there is no effective way to solve this problem. Only use some compromise temporarily. If cultural protection units or collections unit received digital cultural heritage and other information from the digital technology enterprises, information engineering, intangible cultural heritage inheritors or publishers, you need to specify the file format receiving information in a limited range of species. For example, we can restrict the digital information of the content can only using 35 file formats of the most popular. Limited format types can reduce the overall intangible cultural heritage repository complexity and can avoid appearing extremely rare document format in database. This will greatly reduce the the difficulty of the future maintenance, even if the software and hardware environment changes happened in the future. We only face several formats of "migration" problem, rather than dazzling digital files. At the same time, Protection authorities should cooperate with producers of digital information, letting them pay more attention to the format issue, guiding them how to organize their documents and inform them to use what kinds of format that will be helpful to post-maintenance and management. More research and communication, especially effectively communicate with content providers and technology vendors, is the necessary condition for solving multiple formats problems.

\section{Respecting Intellectual Property rights and Establish Collaborative Work Mechanisms}

Intangible cultural heritage protection work should handle issues related to intellectual property rights properly, and facilitating communication and coordination among the main intangible cultural heritage information chain. Intangible cultural heritage protection digital protection is not only a complex management work, but also involves a lot of legal issues. Attributes of information and functionality of intangible cultural heritage and functional determine that it will inevitably face intellectual property issues. We need to know which digital data is the one that the collection units have the right to collect? What information is the one that collection units has the right to publish it on a website, provide public access, download and use? Access control and rights management of digital content is becoming an increasingly complex area for archiving unit libraries, museums and archives of digital information. Intangible 
cultural heritage protection units may have the right to access information on the Internet via electronic networks exist, but does not mean that it is entitled to the information filed in their own data centers.

The private issues of intangible cultural heritage skills not only led to intellectual property issues, but also make it difficult to guarantee the safety of the precious intangible cultural heritage. Some important information of intangible cultural heritage, especially those skilled information that can produce commercial interests, it usually collected private and used by the private to meet the individual needs of the economy. Abroad digital cultural heritage protection agencies suggest: To prevent the loss of valuable digital information the digital protection should be build by the information creators, providers and owners together to build. [14] We need to cooperate with inheritors of traditional skills to protect the information of cultural heritage, which is one of the key of preservation work. It strongly suggests that intangible cultural heritage information store is not only a technical and operational issues, but also an institutional problem. Protectors not only save files and manage information through computers, but also interact, communicate, and monitor with people.

In addition to exchange with owner of the information, the various protection units should also cooperate with each other. All units are trying to organize and archive all the information they can get. In many cases, some duplication of effort not only waste limited human and financial resources, a large number of duplicate information also increased the burden of future information maintenance work, impacting the follow-up work. The protection of intangible cultural heritage requires each agency to coordinate to determine the scope of their work accordance its specific tasks and the ability.

\section{Strengthen the Foundation of Survival}

Intangible cultural heritage as once Social mainstream culture culture has strong social and communal. The survival basis of this kind of social culture is public. Therefore, future work needs to be strengthened in promoting the sense intangible cultural heritage protection, emphasizing the importance of protecting and the public's sense of responsibility and causing more public attention. Internet and digital technology is regarded as panacea in solving the problems facing the intangible cultural heritage protection work in modern society. In fact, the most important factor is the public's support. Intangible cultural heritage is extremely important for all countries and peoples, but this emphasis should not only come from the government. In reality, most of the protection task is assigned to security unit and collection units. In fact, it is enormous difficult to protect the intangible cultural heritage. Cultural heritage requires that all beneficiaries under the bear together and publicizing the importance of protecting these vulnerable public forum information heritage. Only enhance the people's support and understanding, to the intangible cultural heritage protection work, can prevent the constraints of financial and human resources hinder protection work carried out smoothly.

\section{Conclusion}

In network society, intangible cultural heritage protection agencies preserve, display and transmit intangible cultural heritage mainly through effectively to serve the community. The rapid development of digital technology and network greatly improved the efficiency of protection. However, the existing protection work emphasis more on short-term results rather than long-term maintenance and management. Intangible cultural heritage protection mechanism should be improved, public intangible cultural heritage still lacks sufficient interest. The task of protection the intangible cultural heritage is difficult and lack appropriate funding and norms.

\section{Acknowledgment}

The research program is supported by the planning project of philosophy and social science of Zhejiang province (13NDJC164YB) and the fund project of the Humanities and Social Sciences of the Ministry of Education of China (12YJAZH158).

\section{References}

[1] UNESCO: "The protection of intangible cultural heritage" http://www.ihchina.cn/inc/detail.jsp?info_id=50 •

[2] Liu Xiaojian: "From the perspective of information theory: the digital protection of intangible cultural heritage ", Journal of Computer Aided Design \& Computer Graphics, no 1, 2008, pp.117-123.

[3] Taylor Cowan: "creative destruction". Zhiyi Wang transl., Shanghai: Shanghai people press, 2007.

[4] Liu Kuili "Sharing, authenticity and human cultural diversity development of intangible cultural heritage", Journal of Xuzhou Institute of Technology: Social Science Edition , no 2,2010, pp.64-67.

[5] Michael Brown, "Heritage trouble: recent work on the protection of intangible cultural property," International Journal of Cultural Property, (December 2005), pp.40-61

[6] Wang Ying: "Study on high-tech product price protection policy coordination for perishable", Progress of science and technology, no 15,2009, pp97-99.

[7] Yang Daoling: "Discussion on digital collection of disaster recovery strategy", Science and Technology Archives, no 6, 2006, pp45-52.

[8] Wang Yan,Wang Jian, Hu zhiqiang: "The conversion from high to low version database and other language files ", Journal of Taishan University, no 3, 2005,pp 36-39.

[9] Gao bingzhong "Intangible Cultural Heritage the Public Culture ", Research on literature and art, no 2,2008, pp 77-83.

[10] Guo mingzhu: "The traditional collection of digital is coming", Library and information work, no 2, 2009,pp 38-39.

[11] Wang wenzhang, Chen feilong: "The protection of intangible cultural heritage and national culture development strategy", Journal of Huazhong Normal University: Philosophy and Social Sciences Edition, no 2, 2008, pp 81-89.

[12] Zhao xuyao,Zhou qingshan,Zhang wende: "Strategy of building the evaluation index system of network information ecological system", Journal of intelligence, no 2, 2009, pp 303-309.

[13] Yang cheng, Sun shouqian: "Restoration and protection of the Chu culture exhibition in Bianzhong choreography", Chinese Journal of image and graphics, no 10, 2006, pp 1474-1479.

[14] Waters D, Garrett J, “Preserving Digital Information” , Washington DC: The Commission on Preservation and Access, 1996. 